\title{
Solidarity and Cooperation - some perspectives
}

\author{
Avinash De Sousa \\ Research Associate, Department of Psychiatry, Lokmanya Tilak Municipal Medical College, Mumbai. \\ Corresponding Author: Avinash De Sousa \\ E-mail: avinashdes888@gmail.com
}

\section{Introduction}

Solidarity has recently been gaining more prominence in bioethical, public health and global health debates. The history of solidarity is patterned. Throughout its history, the concept has been imbued with different meanings, with the common denominator being that solidarity is a prosocial notion. We define solidarity is as a (shared) commitment to accept responsibility (in the wide sense of the word) to support others with whom people recognise relevant similarities. Defined in this manner, solidarity can be clearly distinguished from related concepts such as altruism or charity [1].

In the context of bioethical policy and practice, solidarity has the potential to ground just, effective public policy and can motivate individuals and governments to participate in programmes intended to alleviate common threats. It primarily means that all individuals must come together and work towards a common cause. There are many instances in health care where solidarity has helped for the greater good of mankind [2]. The following paper shall look at various instances in healthcare where solidarity has resulted in better results for mankind.

\section{Strikes and Violence Against Doctors}

Nowadays with the rising cases of violence amongst doctors there is a growing scenario where doctors rise up together when there is violence against them for no fault of theirs. This has led to a law that has been evoked to protect against violence towards doctors.

It is believed that when the cause is just and backed by the right intentions, any form of agitation is reasonable. The same way a doctor's strike when just and with the right intention of greater good of most doctors is considered fine. The strike must not be political or aimed at political ambitions, it should not be because of one man's ire against the government or an act meant for the aggrandizement of one's ego or a means to show one's power [3].

The criterion of just cause often demands a utilitarian philosophy determinant which demonstrates that ultimately, the beneficial repercussions of the strike on the health system that must outweigh the temporary disruption and suffering caused by it. During the strike it is pivotal that doctors must demonstrate the right intention and they should remain benevolent to their cause while avoiding gall spewing acts that may compromise their just cause [4].

It is very essential that doctor's that strike be assured of success in some way as very often many strikes in the long run prove futile and catastrophic. For example the strike by junior doctors citing an increase in stipends led to the government increasing the stipend by $20 \%$ while medical course fees were hiked within a month of this ruling by $60 \%$. Thus the loss financially was for the doctors who ended up paying more than they did prior to the strike [5].

In strikes, multiple medical bodies must come together and work in harmony towards the common aim without affecting the common man and seeing that no casualties of life result due to the strike. This is one area where solidarity has been used with success for just demands to enhance the quality of life of doctors. There has been a spate of violent incidents all over India against doctors and only when the doctors come together will they be able to put together their human resource to protect the lives of their own comrades while they work towards protecting the lives of other fellow human beings. A doctor is a selfless person but a human being nevertheless and this is something that never must be forgotten when providing service to mankind. 


\section{Global Polio Eradication Programme and Solidarity}

Polio eradication has happened on a war footing across all nations worldwide. The reasons the polio eradication programme was successful was cooperation and coordination between various agencies, public private partnerships, grass root workers being involved and a united effort at an individual, state and national level. Many non governmental organizations joined hands with government bodies and this resulted in united efforts in both rural and urban areas to eradicate polio. There has been also enough of advertising and roping in of national and international celebrities that made the campaign successful and made people move towards the eradication and enhanced attendance at the pulse polio programmes. There has also been a rise in solidarity here which placed solidarity over national pride and resulted in nations getting together towards this common cause [6].

\section{Solidarity and Hospice Care}

Solidarity is also seen in hospice care worldwide. Hospice care involves end of life care where multiple issues may plague the patient in question. The hospice care team is made up of multiple partners starting with the doctors, nurses, ancillary staff, therapists and relatives of the patient that put all personal goals aside and work unitedly towards the development of a holistic care to the patient and catering to his wellbeing at the end of life. The various facets of care that range from medical to social and spiritual are incorporated in one roof and the best support is provided to patients and caregivers for their wellbeing [7].

\section{Solidarity and Disaster Management}

Global humanitarian aid doctors should adopt policies of solidarity with strife-torn and disasterstricken communities rather than charity, and ensure aid workers have the requisite skills to deliver their specific mandates. A catastrophe is always tragic, but we can rescue this thought from it all: we need to find ways to consolidate and reinforce the social capital of our nation. We need to stick together and feel proud of our identity so we may strengthen the bonds that unite us. We all know what happens in times of disaster. The mask of civility and morality constraining our selfish, animal instincts fall away. People panic, mobs form and there's looting, arson and mayhem [8]. When natural disasters hit, the people affected are in need of immediate and swift help. States have developed protocols and services to respond first; however sometimes not even good planning can anticipate the scales of some natural disasters, nor the area or number of people affected. The situation is even worse in countries with outdated protocols and small disaster/emergency budgets. Protecting lives and reducing suffering becomes a case for practicing community solidarity and support in order to reach all those who need help, as international humanitarian aid takes more time to deliver. Multiple agencies need to work together to achieve this aim keeping personal goals aside and only then will results ensue [9].

\section{Solidarity and Dementia Awareness}

Care, building on the foundation of solicitude, includes joy, compassion, commitment, and respect: care rejoices in the existence of the person with dementia, care responds supportively to the needs of the person with dementia ... care is loyal even as the loved one fades from the sphere of familiar self-identity and becomes almost unknowing and therefore unknown, but still remembered [10]. There are six principles that he describes as the core of an ethics of dementia -

- Something can be done for (and with) individuals with dementia.

- Many factors can cause excess disability in individuals with dementia. Identifying and changing these factors reduce excess disability and improve functioning and quality of life.

- Individuals with dementia have residual strengths. Working with them to build on these strengths improves their functioning and quality of life.

- The behavior of individuals with dementia represents understandable feelings and needs, even if the person is unable to express them. Identifying and responding to these needs reduce the incidence of behavioral problems.

- The physical and social environment affects the functioning of people with dementia. Providing the appropriate environment improves their functioning and quality of life. 
- Individuals with dementia and their families constitute an integral unit. Addressing the needs of families and involving them will benefit both the person with dementia and the family.

As the virtue of solidarity moves the caregiver from "doing for" to "being with," it indeed becomes the virtuous mean between the twin vices of neglect of and oppressive care for the person with Alzheimer's disease. It is this Aristotelian mean to which we need to strive [11].

\section{Solidarity and Autism Spectrum Disorders}

It is vital that everyone should be committed to promoting acceptance, encounter and solidarity through concrete support and by encouraging renewed hope, thereby contributing to overcome the isolation and, in many cases, the stigma to which people with autism spectrum disorders are also subjected, and often their families too [12].

This must not be an anonymous or impersonal accompaniment, but one of listening to the profound needs that arise from the depths of a pathology which, all too often, is difficult to diagnose, but - especially for the family - must be accepted without shame or withdrawal into solitude.

In the realm of assistance to people affected by autism spectrum disorders, it would be beneficial to create a regional network of support and services which are comprehensive and accessible. In addition to parents, these should also involve grandparents, friends, therapists, educators and pastoral workers. These figures can help families overcome the feelings, which can sometimes arise, of inadequacy, helplessness and frustration [13].

\section{Solidarity and Ethics}

Solidarity from an ethical standpoint is at various tiers - [14]

Tier 1: Interpersonal level - The first, 'lowest' tier applies to the level of individuals. At that level, solidarity comprises manifestations of the willingness to carry costs to assist others with whom a person recognizes sameness or similarity in at least one relevant respect. The recognition of similarity with one (or more) other people in one relevant respect can take many forms: it entails the awareness of being associated, by choice, by 'fate', or other circumstances, with others.

Tier 2: Group practices - In cases in which a particular solidaristic practice at the inter-personal level becomes so normal that it becomes more widely seen as 'good conduct' in a given situation, it can solidify into forms of institutionalization. This is the case, for example, with self-help groups. On this tier, solidarity can be described as manifestations of a collective commitment to carry costs to assist others (who are all linked by means of a shared situation or cause).

Tier 3: Contractual and legal manifestations - If these values or principles solidify not only into social norms but manifest themselves in contractual or other legal norms, then we have an instance of Tier 3 solidarity, the 'hardest', most fixed, form of solidarity. Examples are welfare state and social welfare arrangements, but also contracts between different private actors and international declarations or treaties.

\section{Conclusion}

Recent work has stressed the importance of the concept of solidarity to bioethics and social philosophy generally. But should it feature in documents such as the Universal Declaration on Bioethics and Human Rights as anything more than a vague notion with multiple possible interpretations. The suggestion that solidarity should feature more centrally in international regulations is a valid one and the concepts of solidarity and the differences between solidarity, justice, equity and cooperation must be a part of routine bioethics curriculums.

\section{REFERENCES}

1. Rehg W. Insight and solidarity: The discourse ethics of Jürgen Habermas. Univ of California Press; 1994.

2. Pensky M. Ends of Solidarity, The: Discourse Theory in Ethics and Politics. SUNY Press; 2009. 
3. Cunningham SA, Mitchell K, Narayan KV, Yusuf S. Doctors' strikes and mortality: a review. Soc Sci Med 2008;67(11):1784-8.

4. Marchildon GP, Schrijvers K. Physician resistance and the forging of public healthcare: a comparative analysis of the doctors' strikes in Canada and Belgium in the 1960s. Med Hist 2011;55(2):203-22.

5. Thomas G. Junior doctors, strikes and patient care in public hospitals. Indian J Med Ethics 2006;3(2):44-5.

6. Emerson CI, Singer PA. Is there an ethical obligation to complete polio eradication?. The Lancet 2010;375(9723):1340-1.

7. Reese DJ, Ahern RE, Nair S, O'Faire JD, Warren C. Hospice access and use by African Americans: addressing cultural and institutional barriers through participatory action research. Social Work 1999;44(6):549-59.

8. Furedi F. The changing meaning of disaster. Area 2007;39(4):482-9.

9. Mathbor GM. Enhancement of community preparedness for natural disasters: The role of social work in building social capital for sustainable disaster relief and management. Int Soc Work 2007;50(3):357-69.

10. Ter Meulen R, Wright K. Family solidarity and informal care: The case of care for people with dementia. Bioethics 2012;26(7):361-8.

11. Bartlett R, O'Connor D. Broadening the dementia debate: Towards social citizenship. Policy Press; 2010.

12. Lindblom A, Carew M, Dindar K, Kärnä E, Soan S, Roos C. Student teacher's attitudes towards educating pupils diagnosed with Autism Spectrum Disorder in the inclusive mainstream classroom. InNERA2016-The 44th Congress" Social justice, Equality and Solidarity in Education", 9-11 March, Helsinki 2016.

13. Harshaw J. Autism and Love: Learning What Love Looks Like-a Response. Practical Theology 2012;5(3):279-86.

14. Rock MJ, Degeling C. Public health ethics and more-than-human solidarity. Soc Sci Med 2015;129:61-7.

Acknowledgements - Nil

Source of Funding - Nil

Conflict of Interest - Nil 